\title{
How to Make Highly Rational Use of Modern Educational Technologies
}

\author{
Li Wang ${ }^{1}$, Xiaoning Wang ${ }^{1}$, Ningyu Liang ${ }^{1}$, Ming Xiao ${ }^{2}$ \\ ${ }^{1}$ Information Engineering College, Shenyang University, Shenyang, China \\ ${ }^{2}$ Experiment Center, Shenyang Normal University, Shenyang, China \\ E-mail: sy-wangli@tom.com,Xmjjy123@163.com \\ Received September 13, 2010; revised October 17, 2010; accepted November 19, 2010
}

\begin{abstract}
Modern educational technology is playing a very important role in information engineering discipline in ordinary universities and colleges. The using of modern educational technology can be classified into instinctive stage and rational stage. In the instinctive stage, users have been aware of the importance of those modern assisted teaching methods and make full application already. In rational stage, the user should not only establish a best teaching environment by using all teaching methods, but also optimize the usage of these methods to get the most powerful effects in class based on specific educational goal. In this paper, how to make highly rational use of modern educational technologies in ordinary universities and colleges is the main topic we discussed. Authors investigate relative educational environment and consequences in their teaching experiences of many years, and conclude from those data by comparing, evaluating and analyzing relative situation.
\end{abstract}

Keywords: Modernize Teaching Technology, Instinctive Stage, Rational Stage, Optimization

\section{Introduction}

Education process mainly includes knowledge content, teaching methods and education technologies. Modern educational technologies such like CAI has become the essential educational method for information engineering study in colleges and universities. Information engineering education has a unique feature of mass information flow in classroom. Hence, the assistance of CAI in class is very helpful. CAI technique is irreplaceable because it can simulate complex dynamic process of engineer implements by animation or images sequences playing and give intuition understanding to students. Therefore, only using CAI instead blackboards and chalk without thinking of its advantages can not be regard as modern educational technologies adoption.

The using of modern educational technology can be classified into instinctive stage and rational stage. In the instinctive stage, users have been aware of the importance of those modern assisted teaching methods and make full application already. Teachers use CAI to show knowledge instead blackboard and chalk, thus, writing time has been saved and the process of teaching can be accelerated which make massive information conveying possible.
Videos are also played in classrooms to help students understanding social or scientific resources directly. All these means can be prepared before class.

In rational stage, the user should not only establish a best teaching environment by using all teaching methods, but also optimize the usage of these methods to get the most powerful effects in class based on specific educational goal. In this stage, simply add knowledge contents or instructions of education tools is not enough. Knowledge contents should be selected and instructed carefully, and instruction tools should be used appropriately, in order to get the best educational result. And the students not only can learn from teachers in classes, but also can learn form virtual classrooms on teaching network built by teachers.

Obviously, as long as we push the teaching process into rational stage, we can gain the best educational results.

\section{Modern Educational Technique Affects on Student}

Nowadays, students growing up with the company of television and network, and conform to image observing, thus, they understand images information better than 
texts, which make them much more sensitive to images in classes.

\subsection{Modern Teaching Techniques}

Modern teaching techniques have following characteristics:

1) Most instruction equipments are electrical;

2) Textbooks are full of images or evolved into video or audio;

3) Teaching methods become more and more multiple.

These characteristics make it unrestricted by time and place. The audio-visual teaching materials make the instructional contents more concrete and direct-viewing. Its vividness is beneficial to active students' sensation and interest of research.

Modern teaching techniques directly assistant and influence the educational level of information engineering subject, and promoted development of information engineering discipline education. No matter in classroom or in extracurricular network, modern teaching assistant means always support the education of the modern science and technology. In information discipline education, modernize teaching technology is used to assist the teaching of basic computer operation technology, algorithmic language, data-base, programming design, MIS design and realization, environment simulation and so on. They play very important roles in education of information engineering. Students are required to handle knowledge above in modern information society. But, it is very difficult for them to understand these courses only by educator's oral explanation. In practice, students need time to explore and exercise. Before this, teacher guidance is the key point to make students comprehend and handle faster. If students' interest can be initiated, then teachers can accomplish the education process more easily. Especially for those schools where applied talents are trained, students can start to study perceptively, and start to learn from specific examples. Such conditioned reflex study function helps students to accept knowledge much easier than conception reading and comprehension, especially for those specialized personnel.

\subsection{View of Students}

From the angle of researching student's study experi- ence, preceding period of time, we have made a questionnaire of students in the information engineering discipline, there being 146 students participate in the investigation. There is a query in it, which teaching form more let you like to study in a classroom? This can choose multiple options. Data is as shown in Table 1 list.

The outcome reflects that students accepted the investigating:

- Over 85 per cent of students fully endorsed face-to-face teaching of teachers.

- Over 90 per cent of them accepted the modernization teaching (assistant) mode.

- A part of them maintain the attitude of welcome for adopting variety forms of teaching.

- Some of them especially like traditional teaching methods.

- Some of them are keen on own learning with multimedia autonomously.

- Fewer of them love to watch teaching video.

In this set of data, we may think like this, in accordance with the choice of most students, synthetical adopting face-to-face education and CAI technology is the most welcome classroom teaching mode for most students [1]. That is, in completing teaching goals, the function of the teaching method is the largest.

\section{Using Educational Technology's Rationally}

Teaching form have changed a lot because of the use of modern education tools: blackboard can be replaced by slides, wall map can be upgraded into videos, books are expand to education repertoire, those description of knowledge changed from language statements to multimedia applications, while teaching contents and materials source changed from teachers to giant Internet educational resources. But teaching media including chalk, textbooks, teaching aids, learning tool etc. still also is the basic teaching tool in classroom.

In education activities, universities and colleges not only pay attention to teacher's knowledge storage, theory culture and experience, but also emphasize the educator's own mastery of knowledge, personal quality and scholarly research achievement, moreover, require educators can accomplish that teaching content optimally combine with methods in classroom.

Table 1. Data list.

\begin{tabular}{cccccc}
\hline & $\begin{array}{c}\text { Lecture While } \\
\text { Demonstrates }\end{array}$ & Traditional Way & $\begin{array}{c}\text { Multimedia } \\
\text { Coursewares }\end{array}$ & $\begin{array}{c}\text { Plays the Recording/ } \\
\text { Video Recording }\end{array}$ & Comprehensive Way \\
\hline Person-time & 61 & 21 & 18 & 13 & 43 \\
Proportion & $41.78 \%$ & $14.38 \%$ & $12.33 \%$ & $8.90 \%$ & $29.45 \%$ \\
\hline
\end{tabular}


Therefore teaching needs rational adopting modern educational technology, which means, only using modern equipment to assist teaching activities in classroom is not enough; it is much more important to help student to solve key points and complex points in knowledge comprehension. The most important part is how to provide a most appropriate teaching environment and teaching assistant measures, so that students can understand course theme easily, proactive participate in discussion on the knowledge.

The educational technology which is with teaching content as the center, in low level, is simply show of text, including concepts, theoretical analysis, chart explanation. But the information engineering discipline teaching content includes not only concepts, theoretical analysis, chart explanation, but also usage of relative electronic equipments, computer simulation tools, programming method and direct observation of realizing design content. This requires teachers' high level educational technology choice, because it needs adding enough practical demonstrations to teaching process. A teacher needs not only to study a course content of this field thoroughly, but also to be creative person in education activities.

In extracurricular education activities, that students learn the related knowledge content is dependent on personal hobbies and interest. Therefore, in order to make students gain staged achievements, educators should divide a whole study process into several stages, and design an autonomous learning software or simulation environment according each stage special requirements. For an example, study software of computer software application, we can cut the whole process into some modules, and each module supports a specific function, which allows students to learn via a series of simple small steps. An achievement of a small function would encourage student to continue their study.

\section{Educational Technique Design for Class}

Teaching activities should be designed before class [2]. Good teaching results depend on eximious education environment. In order to design the best teaching environment, the design of teaching process and assistant way has been teacher's key works before class. So a well organized lesson, can lead students to comprehend the widespread technical application of information science, and can manifest the teacher's excellent teaching ability as well.

\subsection{Best Teaching Environment Design}

Considering signal category curricula, we can use computer to simulate signal system environment, computer plaies a role of validating correctness of the knowledge in classroom. Via watching the simulate process students can understand detail, know how to operate an analog system, which response we can get when different signals access the system and how to establish an analog system which is expected, and so on. The simulation system's assistant demonstrating became irreplaceable. What we are trying to emphasize is: the preparations of the best environment and condition before class. Today, such simulation tools constantly upgrade, which means teachers should keep learning and thinking about the flexible use of these instruments.

Now teachers commonly use modernize multimedia computer as assistant. If it were not possible to supply the using of the fine environment and conditions, educators should try to find some assistants which can be used for media, such as image, chart, table and so on, or adopt other means which can show good assistant effect, helping student better to understand the lesson content. The principle is the way taken as far as possible to be the most effective.

\subsection{Comparations of Instruction Modes}

Example 1 is about the computer class subject teaching. In classroom, teaching assisted tool is multimedia computer. Without interactive software, electronic program's form is manual PPT, which is primarily in text form. From feedback of student in the classroom, it is showed that students focus on teacher's lecture when actual application is operated, but keep drifting away when simple PPT (full of text) shows continually.

Example 2 is about information class subject teaching. Teacher chooses to play some selected high quality lecture video based on subject theme. Teacher makes further explanation about the video contents according to the feedback of students until they have no further problems. The students focus on the lecture theme and teacher's explanation. The teaching effect is better.

Example 3 is about database class subject teaching. Firstly teacher explains database theory by blackboard and chalk, then to use assist with the direct show-how of multimedia manipulation. Students concentrate on the teacher lecture and get better effect.

Example 4 is about the information technology application class subject teaching. In most class time, teacher shows lecture video or PPT. A little explanation was inserted in class. Most students all concentrate on teacher's words. However, due to a longer time curtains block light, students easily fatigued, unfocused.

Some factors are out of teachers' control in the teaching process, for an example, whether students really are interested into this course; whether students really like 
autonomous learning, etc. Therefore these results from examples above are for reference only. Generally speaking, the dynamic content makes the students to concentrate quickly.

\subsection{Optimization of Classroom Teaching Example Design}

Example 1, computer composition structure class course teaching. When introducing the internal structure of a machine, explanation according to object pictures can get better teaching affects than simple language description; video playback with explanation is better than pictures. Operations on actual objects can be selected also-open a computer box covers, and move out the internal components to explain, are much better than the video. Therefore, in conditional case, selecting material object realia is the best option.

Example 2, computer simulation class course teaching. Selecting some actual images to show course content with explanation is better than the description in language. However, simulating on computer directly is much better than images showing. The projection on screen may be very small and the teaching speed might be slow down, but better for students to understand the detail situation and process.

Example 3, programme design class course teaching. To choose appropriate examples is much important than others. Those debugged program segment (including the debug process) can cause student think deeply, help the students to see where, why there is a bug, and how to design to achieve neat program. After class, students can take copies of course contents from teacher, so that they can conduct repetitive learning and further study.

Example 4, Web class course teaching. Web Programming, Web Pages design technique, and so an, it is important to install the computer as a server in classroom for them in time. To show the result of code segment directly can confirm correctness of teaching content. Students directly see a series of the work process, enables the student to be possible to repeat. It is batter than other way.

Generally speaking, teachers should be responsible for their student to selecting optimization examples. Educator's teaching ability decided the ability of optimization. Therefore, pedagogue needs to improve themselves constantly.

\section{Evaluation Standards}

Teachers should review their course design after class, there are normal teaching evaluations from different angles [3]. Here, we made two evaluations faced teachers and students respectively. The evaluations reflect the standard of teaching in terms of a classroom teaching assistant application.

\subsection{Teacher Self-Evaluation}

The authors consider there are 4 points can be used to evaluate teaching assistant application.

- Whether achieve the purpose of teaching plan;

- Whether instructional technology has been used rationally for all and every course contents;

- Whether the students' feedback in classroom is the same as teachers' expectation;

- Whether the use of educational technology can arouse students' interests in on-going studying.

\subsection{Student Evaluation}

Evaluation of students directly reflects current result of teachers' work. But some items need long-term test. Current evaluation mainly including:

- Whether the classroom teaching method can be accepted;

- Whether the use of educational technologies aimed at teaching specific contents;

- Whether no other better technology can replace the current teaching techniques.

In mainstream direction, student's appraisal is consistent with teacher's appraisal. The seven items above in A and B should be taken as solid standards for perfect class design.

\section{Conclusions}

It is very important to enhance modern educational technology application level in information engineering subject teaching. Around the teaching objectives, teachers should create the best teaching environment to implement teaching process and optimize the CAI design, must rationally adopt modern teaching technologies in order to improve the quality of teaching.

Design differently teaching plan in different curriculum and to do essential appraisal, can make the choice of teaching technique suit education object better. Extracurricular network teaching software design can not be ignored. The classroom on Internet online teaching platform similarly wants the science design.

Only use modern educational technologies rationally, educators can make the greatest power in teaching process with the assistant of them, and enable the student to improve their knowledge extent and depth faster in information engineering theory and technology area.

\section{Acknowledgements}

The authors sincerely thank Liaoning Province Educa- 
tion Office and Liaoning Province Leading Group for Education Science Planning for the work supports, and thank Shenyang University and Information Engineering College of Shenyang University for the work supports.

\section{References}

[1] L. Wang, X. N. Wang, J. Ma and N. Y. Liang, "Discuss Rational Integration of Modern Educational Technique and Traditional Pedagogical Model," Proceedings of In- ternational Conference on Computational Intelligence and Software Engineering, Wuhan, Vol. 4, 11-13 December 2009, p. 2.

[2] S. D. Brookfield, X. H. Zhou and N. Hong, “The Skillful Teacher: On Technique, Trust, and Responsiveness in the Classroom,” in Chinese, Zhejiang University Publishing House, Hangzhou, December 2005, pp. 46-57.

[3] Y. L. Sun, "Classroom Instruction Reform and Innovation," in Chinese, Guangdong Education Publishing House, Guangzhou, August 2006, pp. 278-329. 